\title{
University of
Hertfordshire
}

\section{Citation for the published version:}

Tofallis, C. (2019). Which formula for national happiness? Socio-Economic Planning Sciences. DOI: 10.1016/j.seps.2019.02.003

Document Version: Accepted Version

This manuscript is made available under the CC-BY-NC-ND license https://creativecommons.org/licenses/by-nc-nd/4.0/

Link to the final published version available at the publisher:

https://doi.org/10.1016/j.seps.2019.02.003

\section{General rights}

Copyright@ and Moral Rights for the publications made accessible on this site are retained by the individual authors and/or other copyright owners.

Please check the manuscript for details of any other licences that may have been applied and it is a condition of accessing publications that users recognise and abide by the legal requirements associated with these rights. You may not engage in further distribution of the material for any profitmaking activities or any commercial gain. You may freely distribute both the url (http://uhra.herts.ac.uk/) and the content of this paper for research or private study, educational, or not-for-profit purposes without prior permission or charge.

\section{Take down policy}

If you believe that this document breaches copyright please contact us providing details, any such items will be temporarily removed from the repository pending investigation.

\section{Enquiries}

Please contact University of Hertfordshire Research \& Scholarly Communications for any enquiries at rsc@herts.ac.uk 


\title{
Which formula for national happiness?
}

Dr. Chris Tofallis

Published in Socio-Economic Planning Sciences, 2019

DOI: $\underline{10.1016 / i . s e p s .2019 .02 .003}$

\author{
Hertfordshire Business School \\ University of Hertfordshire \\ College Lane \\ Hatfield \\ AL10 9AB \\ UK \\ ormsresearch@gmail.com
}

\begin{abstract}
The World Happiness Report is published by the United Nations Sustainable Development Solutions Network and contains an international ranking of national average happiness, as measured by surveys of personal life evaluations. It also contains an analysis which tries to explain the happiness figures from more than 150 countries using data on six key variables.

That analysis assumes the factors combine in an additive manner and therefore operate independently of each other. By contrast, we explore a multiplicative model, which allows for interactivity or synergy between factors, as well as the possibility of diminishing marginal benefit at higher levels of achievement. We find that this model provides a better fit to the data and is therefore superior in its explanatory power. The implication for policy-makers is that they should focus on improving those factors which are the lowest for their nation as this will provide greater relative benefits to subjective well-being. At an individual level this means focusing on improving conditions for those who are experiencing the lowest levels of well-being.
\end{abstract}

Keywords: Happiness, Happiness Index, Subjective Well-being, Multiplicative Model 


\section{Introduction}

The economics of happiness is a growing field. For example, since 2000 there has been a peer-reviewed Journal of Happiness Studies. The recent bibliometric analysis by Dominko and Verbič (2018) "found a big leap in subjective well-being research" after 2008. According to Graham (2005 p.41) happiness economics is "an approach to assessing welfare which combines the techniques typically used by economists with those more commonly used by psychologists. It relies on surveys of the reported wellbeing of hundreds of thousands of individuals across countries and continents. It also relies on more expansive notions of utility than does conventional economics, highlighting the role of non-income factors that affect well-being". This is not the place to survey the literature, but the reader may refer to the recent book by Frey (2018), the literature review by Dolan et al (2008), as well as the collections of papers edited by Frey and Stutzer (2013) and the Handbook on the Economics of Happiness (Bruni, 2007).

An early quantitative work by Easterlin (1974) was widely discussed and often criticised. It analysed time series data from the USA for 1946-1970 looking at long term trends in national happiness and GDP. He found that "at a point in time happiness varies directly with income both among and within nations, but over time happiness does not trend upward as income continues to grow", Easterlin (2017, p.313). This became known as the Easterlin Paradox. This work has been extended both in time and to other countries in Easterlin (2017), but remains controversial (see for example, the book by Weimann et al, 2016).

A common theme in previous work has been the relationship between happiness and personal income. A very interesting recent study by Jebb et al (2018) presents evidence that there is a ceiling to how much happiness that income can bring and that this is an international effect. Using data on 1.7 million people across 164 countries collected by Gallup World Poll from 2005 to 2016, they find satiation occurs at an income of \$95 000 for life evaluation.

However, there are large differences around the world - in wealthier regions satiation occurs at higher incomes, whilst in Latin America it occurs at just \$35 000. (Interestingly, this seems to tie in with the findings of Rojas (2018) that Latin Americans score higher on happiness than other regions with comparable income levels. Rojas attributes this to strong interpersonal relations with family, extended family, and friends.) Such effects may be explained by people comparing what they have with others locally and sometimes being dissatisfied, thereby stoking a desire for more; there may also be an adaptation effect where, after a time, people take their higher income for granted. Indeed, in some parts of the world it was found that life satisfaction began to fall after the satiation point was exceeded, i.e. there can be a turning point. Level of education was also found to affect the satiation point: those with up to eight years of education had a satiation point of $\$ 70000$, for those with 9-15 years it was $\$ 85$ 000 , and for more than 16 years of education it was $\$ 115000$. Once again, these differences may be explained by social comparisons, together with greater aspirations by the highlyeducated.

In modern times the idea of directing a country's affairs with a focus on Gross National Happiness is attributed to the King of Bhutan. He issued a royal decree in 1986 directing his 
Planning Commission to ensure that "the basis for the evaluation of the achievements of the Sixth Plan is to see whether the people enjoy happiness and comfort".

Happiness economics received great attention following the establishment of the Commission on the Measurement of Economic Performance and Social Progress in 2008 by French President Nicolas Sarkozy. This was led by Joseph Stiglitz, Amartya Sen and Jean-Paul Fitoussi, and so was often referred to as the Stiglitz-Sen-Fitoussi Commission. Its 2009 report was very influential, and the work continued under the aegis of the OECD, which launched its Better Life Initiative on the occasion of its 50th anniversary. This focuses on the measurement of well-being and progress, and has published detailed guidelines on measuring subjective well-being (OECD, 2013). One of its outputs is the Better Life Index which is an interactive online tool that allows the user to compare countries' performance based on their own preferences regarding 11 factors (e.g. housing, income education, etc.). The factors are combined as a weighted sum i.e. an additive model.

Each edition of the World Happiness Report contains essays and analysis by different authors. For example Fortin et al (2015) look at how subjective well-being varies around the world by gender and age, and the 2018 report contains a number of papers on migration. (It shows, for example, that the happiness of a country's immigrants is essentially the same as the rest of that nation's population; indicating that happiness can change by migration.) The WHR should not be confused with the Human Development Index; both are produced by United Nations agencies, but one is more recent than the other: The World Happiness Report has only appeared six times to date, whereas the HDI has been appearing almost every year since 1990. Much of the HDI literature is directed at how the component scores can be combined to produce an index, whereas the WHR well-being scores are obtained directly from surveys carried out by World Gallup Poll. That data has also been also used in other happiness studies, such as that by Nobel laureate Angus Deaton (2008). Confusion should also be avoided with the Happy Planet Index. This has a focus on sustainability and, roughly speaking, involves multiplying subjective life satisfaction with life expectancy and then dividing by the ecological footprint. The data is obtained from the World Values Survey (WVS). This is an alternative dataset which includes a question on happiness on a four point scale ("Taking all things together, would you say you are "very happy", "rather happy", "'not very happy", "not at all happy"), and a separate question on life satisfaction on a ten point scale ("All things considered, how satisfied are you with your life as a whole these days, where 1 means you are 'completely dissatisfied' and 10 means you are 'completely satisfied"). The WVS only covers roughly half the countries of the world, which is why it was not used for the WHR.

Minkov and Bond (2017 p.322) state that "Analysis of WVS data from representative populations in 97 countries led to the conclusion that the strongest predictor of national differences in subjective wellbeing are average differences in life control or freedom of choice endorsed by that nation's population, i.e., the feeling that one controls one's life and can live it as one wishes." Minkov (2009) found from linear regressions that after life control, the next most important variable in predicting life satisfaction was GDP. 
In 2011 the United Nations General Assembly passed a resolution entitled "Happiness: towards a holistic approach to development which stated that "the pursuit of happiness is a fundamental human goal", and:

"Recognizing that the gross domestic product indicator by nature was not designed to and does not adequately reflect the happiness and well-being of people in a country...invites Member States to pursue the elaboration of additional measures that better capture the importance of the pursuit of happiness and well-being in development with a view to guiding their public policies" (United Nations, 2011).

In connection with this, a high-level UN meeting was held in 2012 at which the first World Happiness Report (WHR) was released. The WHR is a publication of the United Nations Sustainable Development Solutions Network and has been published every year since 2012, apart from 2014. It includes a ranking of countries which is sometimes informally referred to as The World Happiness Index (e.g. Carlsen, 2017). This ranking is based on the response to a survey question posed by the Gallup organization in more than 150 countries, which asks:

"Please imagine a ladder, with steps numbered from 0 at the bottom to 10 at the top. The top of the ladder represents the best possible life for you and the bottom of the ladder represents the worst possible life for you. On which step of the ladder would you say you personally feel you stand at this time?" (WHR 2017, Helliwell et al, p.9)

This is known as the Cantril ladder question and the result is taken as a measure of subjective well-being, or less formally, happiness. The 2017 Report averages the results from surveys carried out in the three years 2014-2016. It then attempts to explain the variation across countries by means of these six explanatory variables:

- GDP per capita GDP,

- social support SS,

- healthy life expectancy HLE,

- freedom to make life choices FRE,

- generosity GEN,

- perceived (absence of) corruption PER.

The Report points out that the restriction to these 'key' variables is partly due to the nonavailability of other data across the full range of countries. The data is available at http://worldhappiness.report/ed/2017/

We now describe how these survey variables were measured (WHR 2017, Helliwell et al, p.17):

Social support is the national average of the binary responses ( 0 or 1$)$ to the question: "If you were in trouble, do you have relatives or friends you can count on to help you whenever you need them, or not?"

Data for life expectancy are obtained from World Development Indicators. This is then adjusted to healthy life expectancy using data from the World Health Organization. Freedom is defined as the national average of binary responses to the question "Are you satisfied or dissatisfied with your freedom to choose what you do with your life?" Perception of corruption is the average of binary answers to two questions: "Is 
corruption widespread throughout the government or not?" and "Is corruption widespread within businesses or not?"

Generosity is defined as the residual of regressing the national average of responses to the question "Have you donated money to a charity in the past month?" on GDP per capita.

Figure 2.2 in WHR 2017 presents a ranking of the countries based on their average Cantril ladder score for 2014-2016. Part of that figure is reproduced here in Figure 1 for the top 20 countries. The score for each country is displayed as a horizontal bar which is split into seven coloured segments. Six of these segments are the components explained by a regression of the happiness score on the variables mentioned above. (The corruption score being on a $0-1$ scale is subtracted from 1 to provide a perceived absence of corruption score, which is then multiplied by its coefficient). The seventh segment is made up of a constant (1.85) added to the residual or prediction error. This constant corresponds to the happiness score for a hypothetical country called Dystopia which possesses the worst national average score for each variable, i.e. lowest healthy life expectancy, most corruption, least freedom etc. Thus the sub-bar segments in Figure 1 show the contributions relative to Dystopia.

\section{The 20 Happiest Countries in the World (2014-2016)}
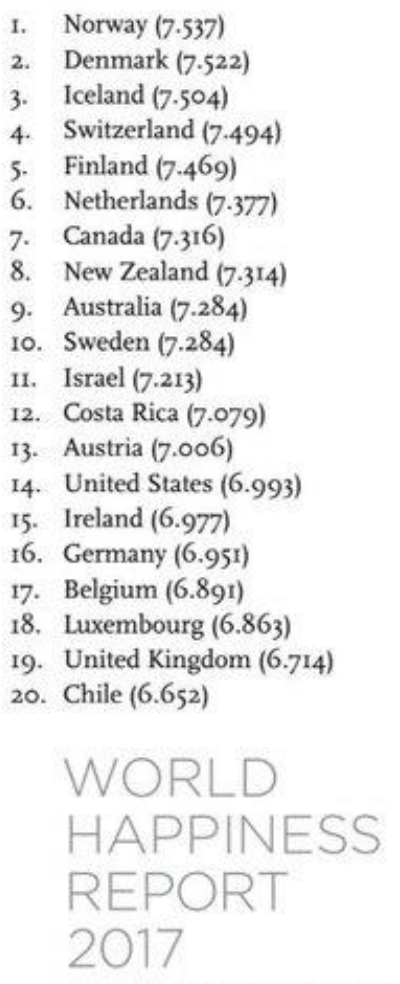

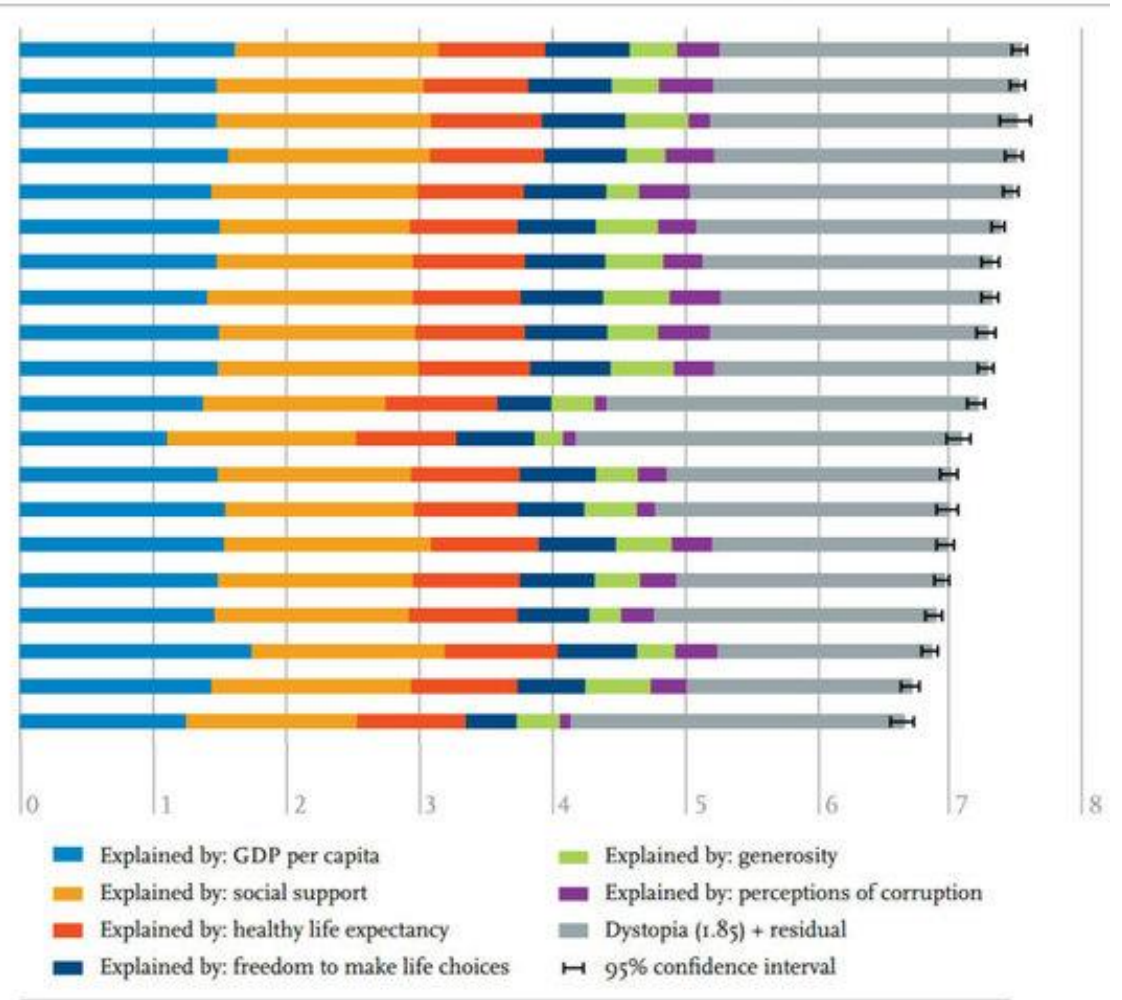

Figure 1. Bar chart representing happiness scores and components explained by linear regression. Source: Helliwell et al 2017 WHR p.20

Our interest in this paper is to see if we can better explain the data on national average happiness by using a multiplicative aggregation of the key variables, rather than the traditional additive one. By adding together the explanatory variables there is an assumption 
that they operate independently of each other: that the effect of changing the level of one variable will be the same irrespective of the levels of the other variables. By contrast, combining the variables by multiplication allows for the effect on happiness of changing one variable to be dependent on the current level of that variable as well as of the others. This is sometimes referred to as an interactive or synergistic effect. We can compare the two models statistically by how well they explain the happiness data that has been collected. If the new model is superior then it will be an indication that the components operate synergistically rather than independently of each other. The model itself will provide a better grasp of how changes in the explanatory factors will affect national happiness. This will be useful to those policymakers who are interested in which factors to focus on.

The structure of the rest of the paper is as follows: In the next section we present the data for each explanatory variable in turn plotted against national subjective happiness. Section 3 looks at a conventional additive (linear) model for explaining the happiness results, whilst Section 4 presents the proposed multiplicative model together with reasons for using it. The results for this new model appear in Section 5, after which we have the discussion, conclusion, and implications for policymakers.

\section{Individual relationships}

We now present scatterplots of the happiness score for each nation against each of the key variables. Reasons for doing this include: to confirm that there is a positive correlation in each case, to observe its strength, to see if any relationship is apparent (curved or otherwise), and to detect the presence of outliers. We do this in Figures 2 to 7, where the vertical axis represents the national average subjective well-being score. We use data consisting of one average figure per country obtained from WHR2017.

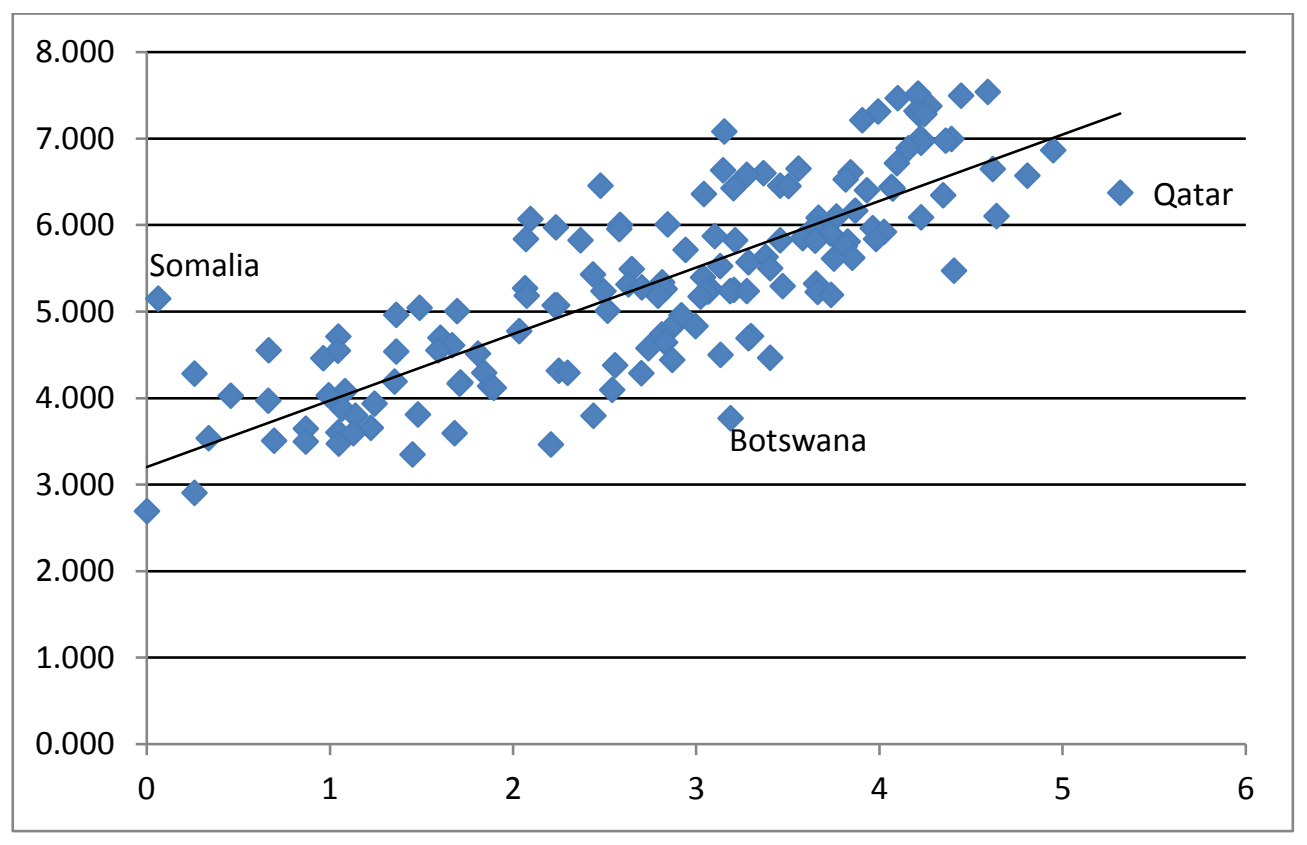

Figure 2 Happiness (y) versus log(Gross domestic product per capita) on $x$-axis. $R^{2}=0.66$. (Quadratic model $R^{2}=0.67$ ) 
From Figure 2 we see that there is a strong linear relationship with log (GDP per capita). This is apparent from the fact that $66 \%$ of the variation in happiness is explained by a straight line relationship. We note that taking the logarithm allows us to model the well-known fact that there is decreasing marginal returns for happiness as income rises i.e. for countries where income is high, an extra unit of money does not improve happiness as much as in a poor country.

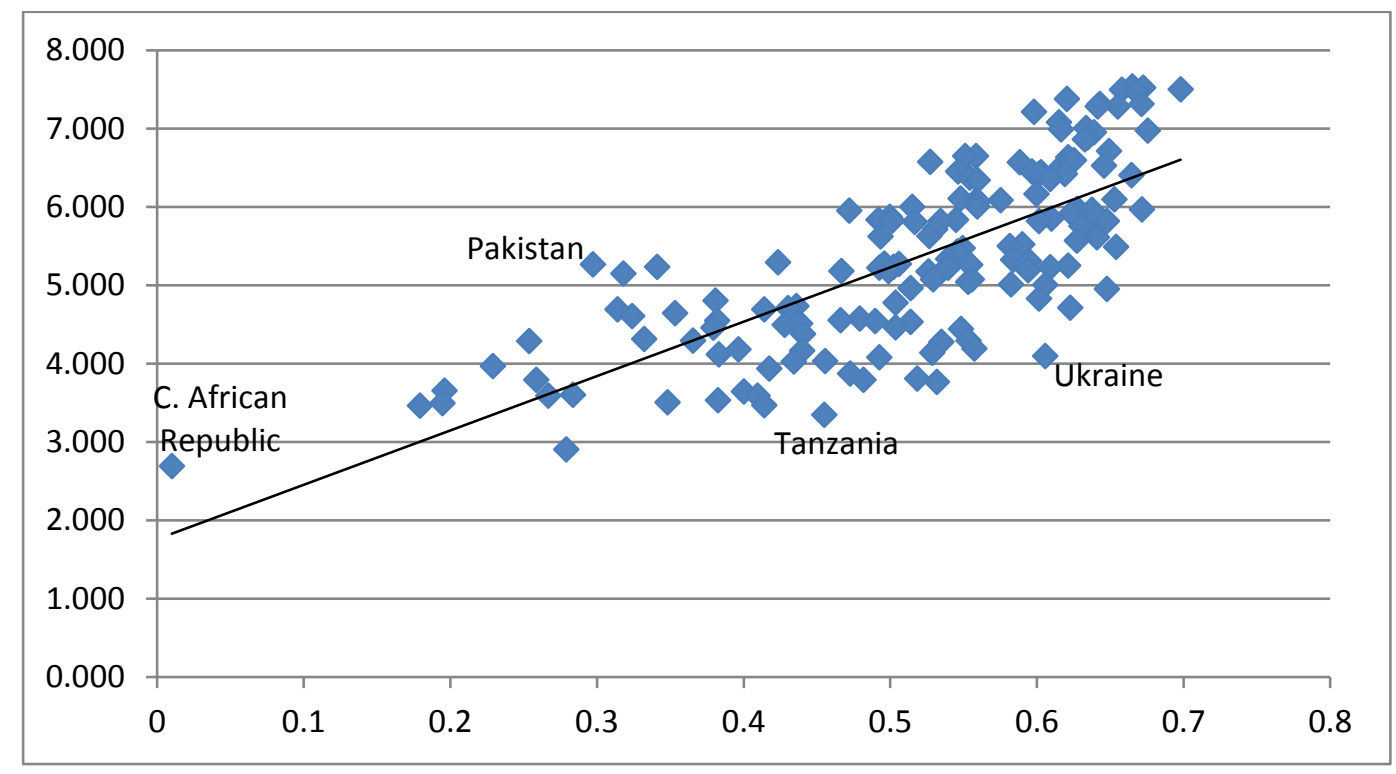

Figure 3. Happiness (y) versus social support $(x) \cdot R^{2}=0.567$. (Quadratic model $R^{2}=0.605$ )

Social support (Figure 3$)$ is also well-correlated with happiness $(r=0.75)$, with a simple linear expression explaining nearly $57 \%$ of the variation across nations, whilst a quadratic relationship explains $60.5 \%$.

Healthy life expectancy, as might be expected, has a high correlation with happiness (0.78), so that a simple linear model explains $61 \%$ of the variation across countries, see Figure 4. 


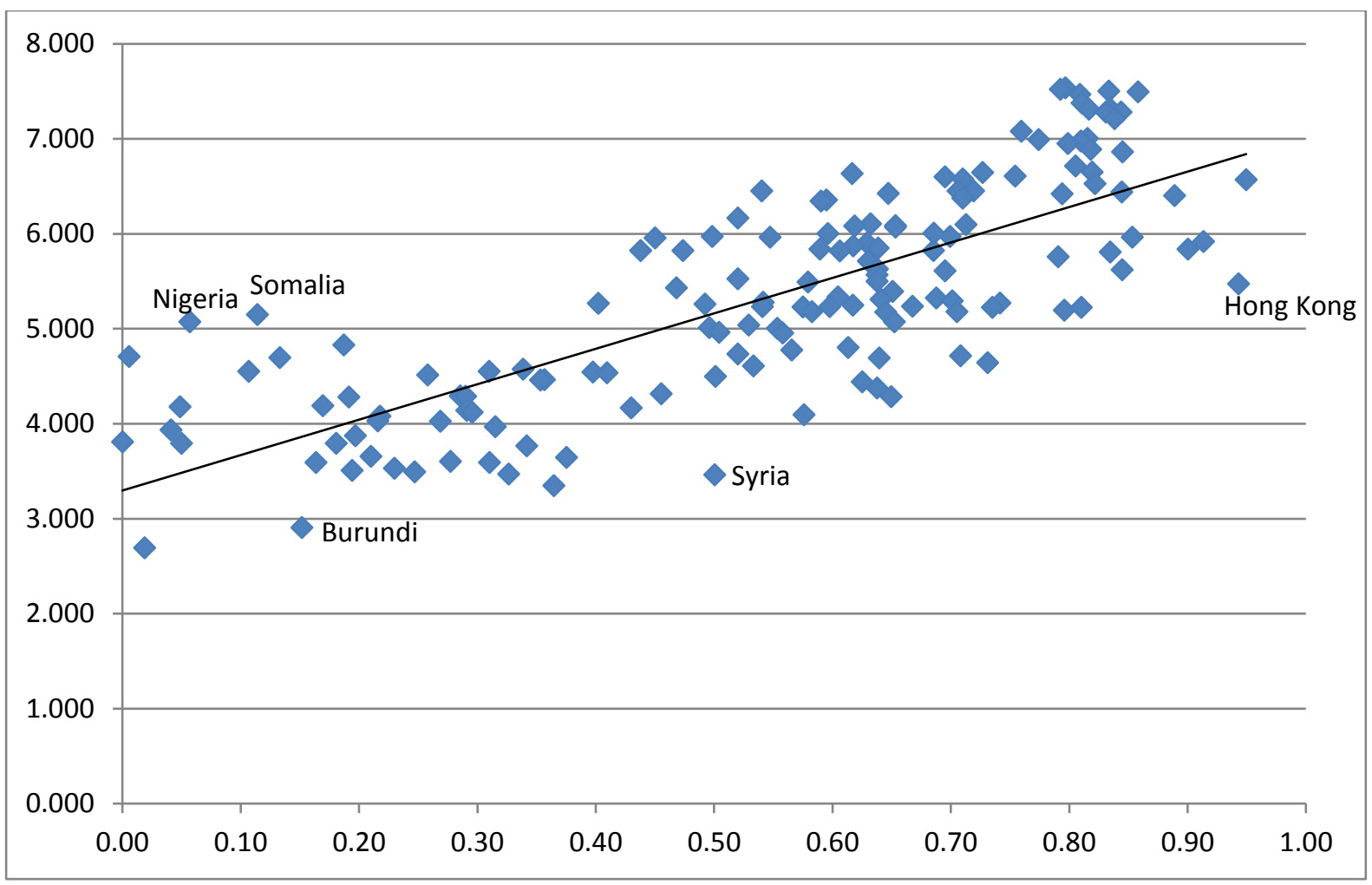

Figure 4. Happiness $(y)$ versus HLE, healthy life expectancy $(x) \cdot R^{2}=0.61$. (Quadratic model $R^{2}=0.63$ )

Interestingly, freedom to make life choices has a lower correlation (0.57) with happiness than any of the above three variables. Figure 5 shows that a trend is apparent but there is a wide scatter on either side of the regression line. Note however that the survey question only offered two possible responses: satisfied and not satisfied.

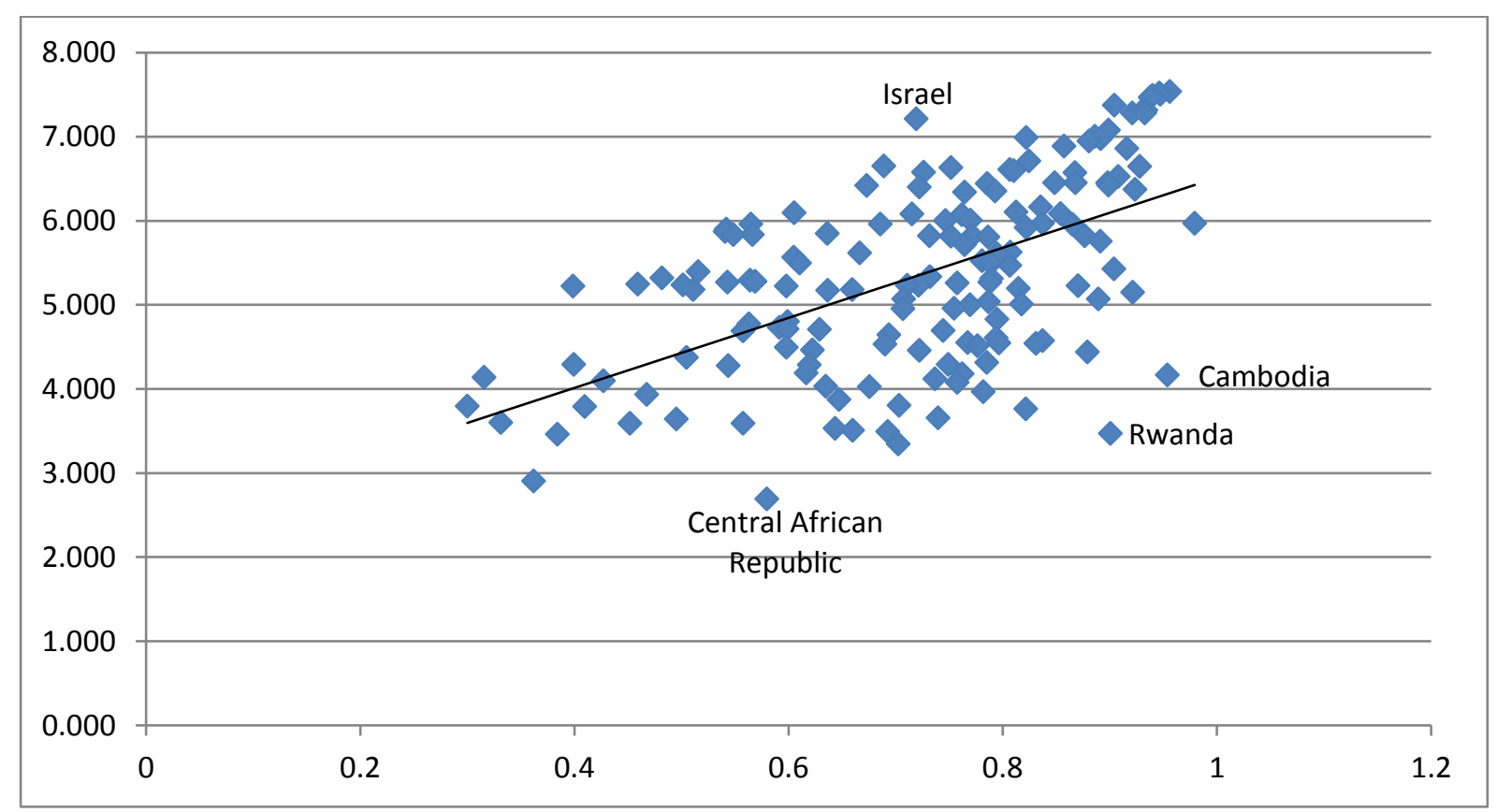

Figure 5. Happiness $(y)$ versus Freedom to make life choices $(x) . R^{2}=0.325$. (Quadratic model $R^{2}=$ $0.34)$ 
There is almost no correlation between happiness and the generosity variable as seen in Figure 6 . This could be due to the way generosity was estimated. It was taken as the unexplained residual after regressing the national average response to the question "Have you donated money to a charity in the past month?" on GDP per capita. This is inadequate for a number of reasons, most notably because it ignores the fact that one can be generous to one's friends and neighbours without necessarily donating to a charitable organization.

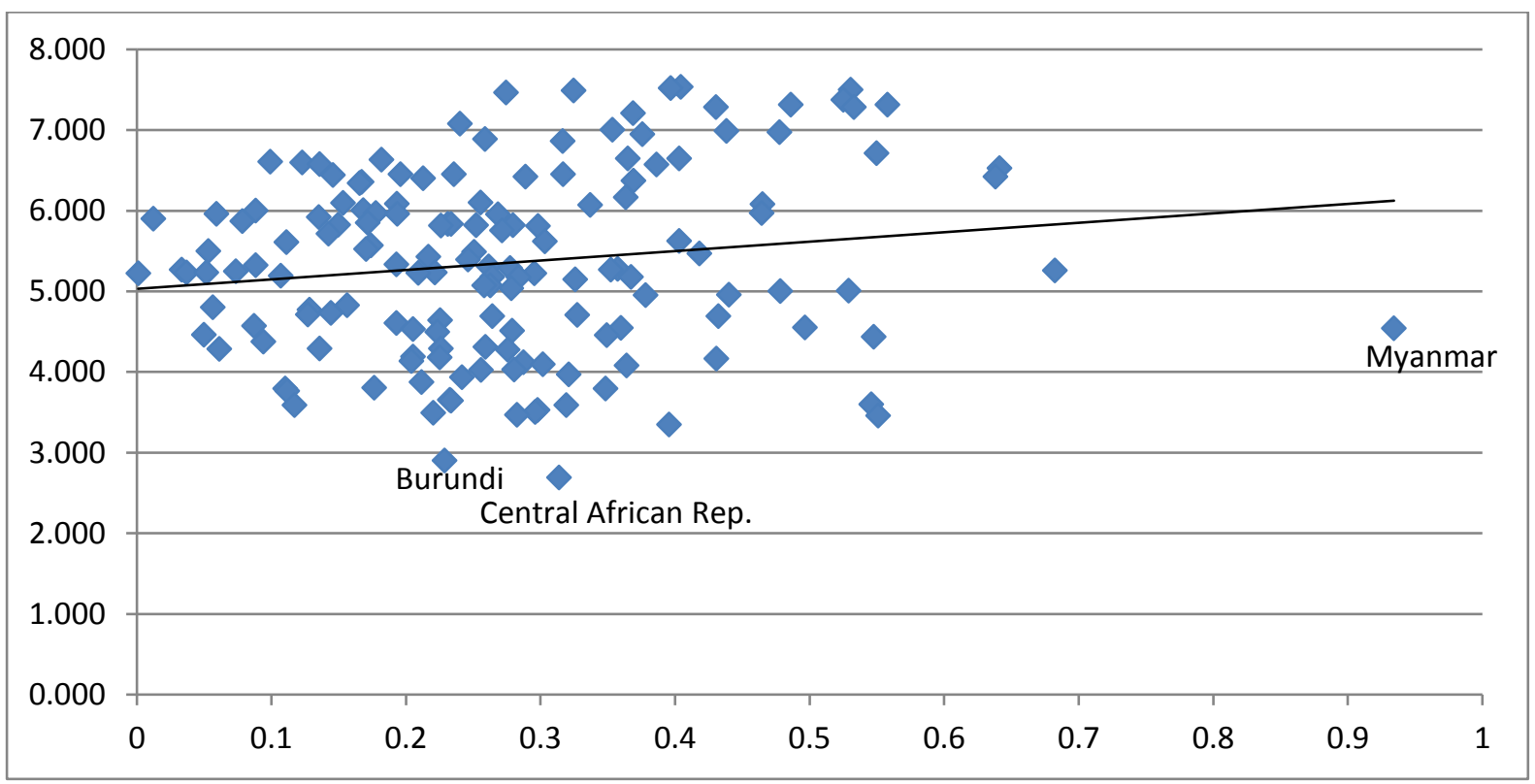

Figure 6. Happiness (y) versus generosity $(x) . R^{2}=0.024$. (Quadratic model $R^{2}=0.025$ )

Finally the plot with the absence of perceived corruption is displayed in Figure 7. There is a large and very scattered cloud of points on the left side of the scatter-graph, followed by a smaller set of points which give an indication of a trend. $\mathrm{R}^{2}=0.18$. A noticeable outlier is present at lower right, corresponding to Rwanda.

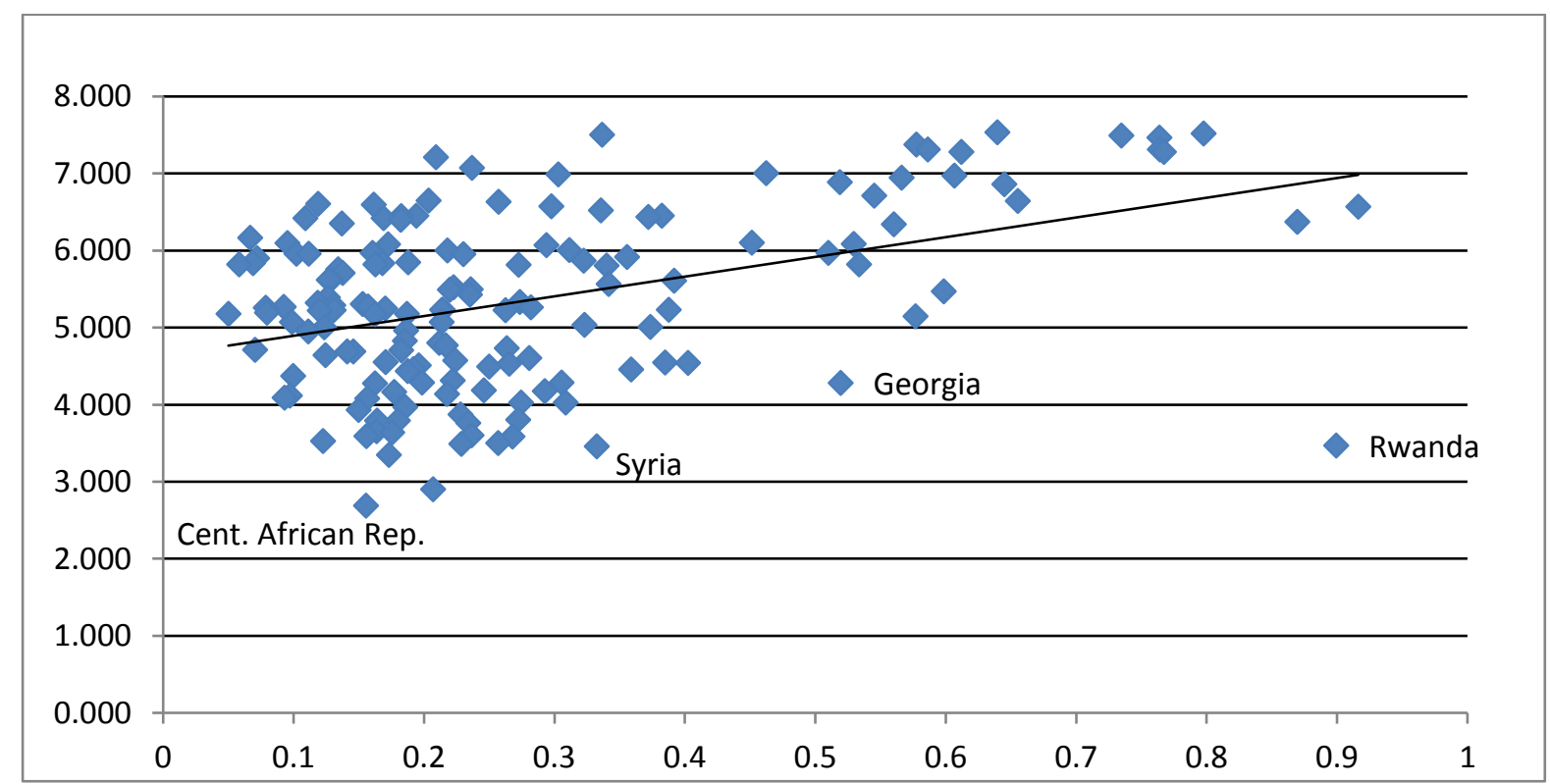


Figure 7. Happiness $(\mathrm{y})$ versus Absence of perceived corruption $(\mathrm{x}) \cdot \mathrm{R}^{2}=0.184$. (Quadratic model $\mathrm{R}^{2}=$ $0.186)$

The latest World Happiness Report (2018) includes supporting data for the three separate years 2015-2017. This enabled us to deduce the correlation Table 1 together with significance results based on three observations per country, one each for years 2015-2017. The correlation figures are in broad agreement with the above results, with HLE, Social Support and GDP having the highest correlations, exceeding 0.7, with happiness.

\begin{tabular}{|c|c|c|c|c|c|c|c|c|}
\hline & & Happiness & $\begin{array}{l}\text { Social } \\
\text { support } \\
\end{array}$ & $\begin{array}{l}\text { Healthy life } \\
\text { expectancy }\end{array}$ & Freedom & Generosity & Corruption & GDP per capita \\
\hline \multirow[t]{2}{*}{ Happiness } & Pearson Correlation & 1 & $.742^{* *}$ & $.758^{*}$ & $.540^{*}$ & $.151^{* *}$ & $-.444^{* *}$ & $.719^{* *}$ \\
\hline & Sig. (2-tailed) & & .000 & .000 & .000 & .002 & .000 & .000 \\
\hline \multirow[t]{2}{*}{ Social support } & Pearson Correlation & $.742^{* *}$ & 1 & $.672^{* *}$ & $.383^{* *}$ & .066 & $-.250^{* *}$ & $.579^{* *}$ \\
\hline & Sig. (2-tailed) & .000 & & .000 & .000 & .183 & .000 & .000 \\
\hline \multirow[t]{2}{*}{ Healthy life expectancy } & Pearson Correlation & $.758^{* *}$ & $.672^{* *}$ & 1 & $.326^{* *}$ & .008 & $-.326^{* *}$ & $.698^{* *}$ \\
\hline & Sig. (2-tailed) & .000 & .000 & & .000 & .877 & .000 & .000 \\
\hline \multirow[t]{2}{*}{ Freedom } & Pearson Correlation & $.540^{* *}$ & $.383^{* *}$ & $.326^{* *}$ & 1 & $.313^{* *}$ & $-.488^{* *}$ & $.407^{* *}$ \\
\hline & Sig. (2-tailed) & .000 & .000 & .000 & & .000 & .000 & .000 \\
\hline \multirow[t]{2}{*}{ Generosity } & Pearson Correlation & $.151^{* *}$ & .066 & .008 & $.313^{* *}$ & 1 & $-.355^{\star *}$ & $.153^{* *}$ \\
\hline & Sig. (2-tailed) & .002 & .183 & .877 & .000 & & .000 & .002 \\
\hline \multirow[t]{2}{*}{ Corruption } & Pearson Correlation & $-.444^{* *}$ & $-.250^{* *}$ & $-.326^{* *}$ & $-.488^{* *}$ & $-.355^{* *}$ & 1 & $-.610^{* *}$ \\
\hline & Sig. (2-tailed) & .000 & .000 & .000 & .000 & .000 & & .000 \\
\hline \multirow[t]{2}{*}{ GDP per capita } & Pearson Correlation & $.719^{* *}$ & $.579^{* *}$ & $.698^{* *}$ & $.407^{* *}$ & $.153^{* *}$ & $-.610^{* *}$ & 1 \\
\hline & Sig. (2-tailed) & .000 & .000 & .000 & .000 & .002 & .000 & \\
\hline
\end{tabular}

Table 1. Correlations between variables used in WHR2018. This table is based on three observations per country, one each for the years 2015 to 2017. (** indicates correlation is significant at the 0.01 level, 2-tailed).

\section{Additive happiness model based on linear regression}

The data used for the 2017 analysis is available as an Excel spreadsheet downloadable from the WHR website: http://worldhappiness.report/ed/2017/ This does not give the raw data but provides the contribution of each term in the regression model below, specifically: (value of variable - lowest observed value) multiplied by its coefficient, (also displayed as the sub-bars in Figure 1). The WHR adds together the lowest observed value for each variable and combines this into the constant; this figure refers to Dystopia - an imaginary country which has the worst observed level of each factor, and acts as a form of benchmark. The linear regression model presented in the 2017 World Happiness Report (Statistical Appendix, Helliwell, Huang, \& Wang, 2017, Table 13) is as follows: 
Predicted National Happiness $=$

$1.85+0.352 \log \mathrm{GDP}+2.341 \mathrm{SS}+0.028 \mathrm{HLE}+0.969 \mathrm{FREE}+0.898 \mathrm{GEN}-0.536 \mathrm{PER}$

(For the perceived corruption variable, PER note that the largest observed national value of corruption is subtracted from each observation, thus giving a negative figure; multiplication by a negative coefficient makes the contribution positive. This can be interpreted in terms of the perceived absence of corruption. Interestingly this variable's coefficient was the only one that was not significant at the $5 \%$ level.)

Given that some of the above explanatory variables have a strong connection with the happiness scores, as indicated by the coefficient of determination (R-squared values up to $66 \%$ ), one might expect that when combined together in a multiple regression one might obtain an impressive result. In fact WHR2017 reports an R-squared of 74\% for their multiple linear regression. The reason for this, possibly disappointing, result is that some of the key variables are correlated with each other, and so overlap in their explanatory power. This is the common problem of multicollinearity. Details of the correlations can be viewed in Table 1 . One observes a cross-correlation of 0.7 between healthy life expectancy and GDP per capita, and 0.67 between healthy life expectancy and social support. This trio of variables appears to be providing much information which is in common as opposed to variable-specific.

In general, as this is an additive model it implies that each unit increase in one of the variables is expected to produce a change in happiness given by the associated coefficient. Moreover, this is predicted to occur independently of the levels of the other variables. The model does not allow for any interaction between the factors.

\section{Method: Model using a multiplicative functional form}

One drawback of using simple linear terms in a model is that it assumes each unit increase in a factor will always produce the same improvement in benefit, irrespective of how much has already been achieved. It also assumes that each factor operates independently of the others, as if there is no interaction between them. Therefore, rather than add $\left(\sum\right)$ explanatory variables to model the happiness score, we now explore multiplying ( $\Pi$ ) them together, in an effort to overcome these issues.

One advantage of a multiplicative model is that it automatically accounts for the possibility of decreasing marginal benefits (or utility) for any factor. The law of diminishing marginal utility is sometimes referred to as Gossen's first law, in tribute to Hermann Gossen (18101858) who laid down some of the foundations which led to utility theory. The WHR uses the $\log$ of GDP as an attempt to deal with marginal returns for that variable alone, but a multiplicative model has the flexibility of an adjustable parameter for each variable which can model the degree to which this effect is present.

In the world of composite indices an 'early adopter' of this multiplicative approach was the Human Development Index (HDI) of the United Nations Development Programme (UNDP). This combines data on life expectancy, years of education, and income per capita to produce 
an annual score for each country. In the early years these components were added together (after some normalization to the 0 to 1 range). This was criticised in various quarters, for example Herrero et al (2010) pointed out that according to this model, however short your life expectancy was, you would be willing to sacrifice even more of it in exchange for income at a constant rate. Sagar and Najan (1998, p.252) recommended multiplicative aggregation because 'the more severe the deprivation on any dimension, the more difficult it is to have a high HDI... This better addresses UNDP's concerns about focusing on the state of the more vulnerable segments of society in determining the level of human development in any country'. Tofallis (2013, p.1329) illustrates this idea in terms of impact on the outcome thus: "Consider an increase of 0.1 in one of the components. This would be a much more significant change for a country which has shifted from 0.1 to 0.2 on this component, than for a more developed country that improved from 0.8 to 0.9 . Under the additive scheme both countries would achieve the same increase in the overall score, whereas under the multiplicative scheme the overall score would rise by a greater amount for the less developed country - it would reflect the fact that it had experienced a greater percentage change." The United Nations Development Programme was persuaded by such arguments, and since 2010 the components have been combined by multiplication to produce HDI scores. (A more detailed comparison of the two aggregation approaches for general purposes can be found in Tofallis, 2014).

We note that the HDI differs from what we are doing here in one important respect. The HDI generates a score using data on three components, whereas we are trying to model the known happiness scores using explanatory variables. Nevertheless it is noteworthy that there is a significant correlation between the two of 0.77 (WHR 2013, Helliwell et al, p.34).

In the WHR multiple linear regression a coefficient was attached to each variable $\left(\mathrm{x}_{\mathrm{i}}\right)$; instead of that we will now have exponents $\left(b_{i}\right)$ i.e. powers of the variables. Thus the new multiplicative model is:

$$
\text { Predicted Happiness }=\text { constant }+b_{0} \Pi x_{i}^{b_{i}}
$$

where the symbol $\Pi$ refers to the product of the explanatory variables raised to their individual powers. We assume a squared residual as the loss function i.e. least squares, as with the linear regression presented in WHR.

\section{Results}

As noted in section 3 above, the 2017 WHR spreadsheet does not provide raw data, but it contains the numerical components for each term that arises in the linear regression. From these figures we were able to deduce the data for the six explanatory variables for 155 countries by dividing by the regression coefficients (given in Table 13 of the WHR2017 Statistical Appendix and then adding back the minimum level for each variable (as given in Table 6 of that Appendix). An exception to this was the generosity variable GEN. Unusually, this was defined in the form of a residual with a mean of zero. We have not added back the 
lowest value (which is negative) in order to keep all values positive. Positive data is necessary for a multiplicative aggregation.

The above multiplicative model was employed in a (nonlinear) regression to see how well it fits the happiness (subjective wellbeing) survey data. This was carried out using the IBM SPSS software. This resulted in the following:

$$
\text { Predicted Happiness }=2.087+0.075\left[\mathrm{GDP}^{0.076} \mathrm{SS}^{0.801} \mathrm{HLE}^{0.810} \mathrm{FREE}^{0.296} \mathrm{GEN}^{0.011} \mathrm{PER}^{0.02}\right]
$$

The six variables on the right of the equation appear in the same order as those listed in the Introduction above. The variable GDP here is the Gross Domestic Product per capita without logs because the diminishing returns feature is captured by an exponent below unity, and so logs are not required. (The goodness of fit was lower, at $76.6 \%$ when the logged variable was tried).

The goodness of fit of the above model is $82.4 \%$. In other words $82.4 \%$ of the variation in the happiness scores across countries is explained by this model. This is an improvement on the 74\% reported in the World Happiness Report 2017 for the linear model. It corresponds to an $11 \%$ gain in relative explanatory power (since $(82.4-74) / 74=11.35 \%)$. More detailed statistics for the regression are reported in Table A1 in the Appendix.

We observe that all exponents in the above model are positive, as one would expect. The exponents can be interpreted as elasticities i.e. the percentage change in happiness for a unit percentage change in that variable. It is notable that the exponents for healthy life expectancy and social support are the highest, and roughly similar in size.

An exponent of zero would indicate a variable which does not affect happiness. The exponent closest to zero here is that of generosity at 0.011 . It is perhaps not surprising that it is not contributing much given the way this was defined and also by the fact that it did not show any obvious relation in the scatter-graph with happiness. When it was removed from the multiplicative model the goodness of fit figure was unchanged. The exponent for the perceived absence of corruption variable was the next lowest at 0.02 . When this was also removed from the model the goodness of fit was $82.2 \%$, i.e. almost unchanged. The resulting four variable model is:

Predicted Happiness $=2.401+0.041\left[\mathrm{GDP}^{0.087} \mathrm{SS}^{0.900} \mathrm{HLE}^{0.905} \mathrm{FREE}^{0.380}\right]$

Comparing with (3), the rank order of the exponent magnitudes is unchanged, with that for GDP being lowest. This indicates that although there will always be a benefit in raising this factor, its marginal impact will gradually diminish as higher levels are attained. It is interesting to note that Carlsen's (2017) analysis of the WHR data also concluded that "GDP apparently plays only a minor role", when using the very different approach of partial order methodology. Detailed regression statistics for equation (4) appear in the Appendix, together with similar material for equations (5) and (6) below. 
While this paper was being processed, the 2018 edition of the World Happiness Report was released (Sachs et al, 2018). This provided us with an opportunity to see if a multiplicative model would be as successful when using the latest data. The descriptive statistics for the variables in the 2018 ranking are displayed in Table 2 . The additive (linear) regression results to explain the happiness scores together with detailed statistics are shown in Table 3 . The latter were kindly provided by Prof. Haifang Huang, one of the authors of WHR2018 Statistical Appendix, and relate to the main ranking in Figure 2.2 of that report.

\begin{tabular}{|c|c|c|c|c|c|}
\hline & Mean & Median & Standard Deviation & Minimum & Maximum \\
\hline Happiness & 5.376 & 5.378 & 1.120 & 2.905 & 7.632 \\
\hline Log of GDP per person & 9.253 & 9.447 & 1.212 & 6.474 & 11.693 \\
\hline GDP per person & 18970 & 12674 & 19962 & 648 & 119749 \\
\hline Healthy life expectancy & 62.67 & 64.22 & 7.76 & 43.99 & 75.72 \\
\hline Social support & 0.802 & 0.820 & 0.123 & 0.306 & 0.977 \\
\hline Freedom to make life choices & 0.757 & 0.789 & 0.137 & 0.374 & 0.984 \\
\hline Generosity, without adjustment for GDP & 0.300 & 0.259 & 0.178 & 0.034 & 0.900 \\
\hline Perceptions of corruption & 0.740 & 0.797 & 0.182 & 0.103 & 0.947 \\
\hline
\end{tabular}

Table 2. Summary statistics for the national average for each variable used in the WHR 2018 ranking. Calculated from Supporting Factors sheet of WHR2018 Chapter2 OnlineData spreadsheet, http://worldhappiness.report/ed/2018/

\begin{tabular}{|c|c|c|rl|}
\hline Variable & Coefficient & Std. error & \multicolumn{2}{|c|}{ 95\% Conf. Interval } \\
\hline LogGDP & 0.2939 & .0956 & .1048 & .4830 \\
\hline Social support & 2.6250 & .4552 & 1.7250 & 3.5250 \\
\hline HLE & 0.0310 & .0144 & .0025 & .0596 \\
\hline Freedom & 1.5603 & .3695 & .8297 & 2.2908 \\
\hline Generosity & 0.3129 & .3646 & -.4079 & 1.0337 \\
\hline Corruption & -0.5180 & .3384 & -1.1872 & .1512 \\
\hline constant & -2.1781 & .6105 & -3.3853 & -.9709 \\
\hline
\end{tabular}

Table 3. Regression statistics for the additive model using the WHR2018 data. We see that two of the variables, generosity and corruption, are not significant at the 5\% level. The Rsquared goodness of fit statistic was $76 \%$. These results were kindly provided by Prof. Haifang Huang, one of the authors of WHR2018 Statistical Appendix. 
Page 18 of the report explains that from their additive regression model 'the largest single part (35\%) comes from social support, followed by GDP per capita (26\%) and healthy life expectancy (17\%), and then freedom (13\%), generosity (5\%), and corruption (3\%).'

The low contributions of the last two factors is notable and their coefficients were also not statistically significant.

Turning now to multiplicative model using the data in WHR2018. The resulting model from the SPSS nonlinear regression using all six explanatory variables was:

Predicted Happiness $=2.778+0.013\left[\mathrm{GDP}^{0.093} \mathrm{SS}^{1.158} \mathrm{HLE}^{0.999} \mathrm{FREE}^{0.506} \mathrm{GEN}^{0.037} \mathrm{PER}^{0.020}\right]$

The goodness of fit as measured by $\mathrm{R}^{2}$ was $82.4 \%$ which is almost identical to the figure of $82.3 \%$ for equation (3) using the 2017 report.

Once again we explored removing the low correlation variables GEN and PER and found that the goodness of fit was almost unchanged at $82.3 \%$ with the four remaining factors being statistically significant at the $5 \%$ level. The model being:

Predicted Happiness $=2.297+0.01\left[\mathrm{GDP}^{0.094} \mathrm{SS}^{1.207} \mathrm{HLE}^{1.035} \mathrm{FREE}^{0.537}\right]$

It is notable that the exponents for healthy life expectancy and social support are again the highest. Moreover, the fact that their value is in the neighbourhood of unity indicates that improving these factors will improve happiness without suffering diminishing marginal benefit.

\section{Discussion and Conclusion}

To date, regressions attempting to explain national differences in happiness have been additive in nature, as pointed out in the review by Dolan et al (2008); see also Minkov (2009), Minkov and Bond (2017), Ye et al 2015 and references therein. The contribution of this paper has been to introduce a multiplicative model. Our analysis provides evidence that such a model provides superior explanatory power compared to traditional linear regression models - i.e. such a model provides a better fit to the data when the same variables are considered. This implies that the factors contributing to subjective well-being do not combine independently of each other as an additive model assumes. Rather, the effect of a change in one factor is dependent on the current level of that factor, as well as of the other factors.

We now look at some shortcomings connected with the various explanatory factors and their measurement, as used in the WHR, with a view to improvements for future investigations. We found that levels of corruption and generosity had little correlation with national happiness, and that removal of these variables from the model had almost no effect on its predictive power. However, this may be related to how these quantities were estimated. 
Corruption was based on 'yes or no' questions and so could not provide any information on the degree of corruption present. The generosity measure was based on whether people had contributed to a charity in the last month. While this practice may not be unusual in some societies, it is unlikely to be the case worldwide. Measuring personal generosity in a different way might lead to a clearer result, or it may simply be that it is not a contributor to happiness; it may be the perceived generosity of other people that matters.

The WHR uses GDP per capita, but it is perhaps more appropriate to use GNI (gross national income) per capita which places more focus on income rather than production. This is because GNI also includes income received by residents of a country by foreign firms while income paid to foreign employees is subtracted. GNI will be higher than GDP if a country receives a large amount of foreign aid, and will be lower if foreigners control a large proportion of a country's production. In 2010 the UN Human Development Index switched to using GNI in preference to GDP.

The data for the freedom and social support variables came from survey questions which only allowed for two responses in each case. This is rather restrictive and information on the level would be more informative.

Another possible shortcoming of this analysis is the restriction to six explanatory variables. Future work could explore other factors that might contribute to subjective wellbeing. Additional variables might include data on housing, level of education, crime levels, unemployment, and access to healthcare. A potential difficulty with this would be to obtain such data for more than 150 countries.

One more proposal comes from a guest editor for this journal's special issue: "One could perform a factor analysis to identify constructs that explain variation in the self-assessed well-being measure that may be distinct from the six explanatory variables used in the World Happiness Reports to date."

Why did our multiplicative model perform better than the additive one used by the WHR? Firstly, because it does not assume the factors operate independently of each other. Secondly, a multiplicative model ties in better with our understanding of how increasing levels can have a gradually decreasing marginal return. This is well-established in relation to income (Layard et al 2008). More generally, psycho-physical research shows that people are more aware of relative change rather than absolute change. The work of Stevens (1970) and others on the relation between subjective perception of a change and actual physical change, shows a power law relationship. This is modelled by having the factors raised to powers in our proposed model. Stevens' data supporting a power law meant that it superseded the WeberFechner logarithmic law relating stimulus to response. 'Human beings generally perceive relative gains and losses, that is, gains and losses in relation to the levels from which the move starts' (Lootsma, 1996, p.472). For this reason it is not enough to raise one factor to a very high level (perhaps because it is easier to do so) and leave another very low. Greater relative benefit is obtained when the lowest factors are improved. An additive aggregation does not model this effect because it assumes the benefit of increasing a factor by one unit is always the same irrespective of how much you already have.

An interesting analogy to this is due to Kondraske (2011) in the context of valuing diamonds. Traditionally, their price is dependent on the four Cs: carat (a unit of weight), clarity, colour, and cut. He regressed price data for 257 diamonds on their scores for the four Cs. The goodness of fit for the multiplicative model was $85 \%$, but for the additive model it was much 
lower, at $28 \%$. He concluded that the multiplicative model "reflects that price will be low if any one of the four factors is poor and that a highly priced (high quality) diamond requires high ratings for all four factors". From our analysis this diamond phenomenon appears to also apply to human happiness.

The large-scale collection of data by Gallup World Poll across 155 nations, which asks people directly how they feel, provides a valuable resource for study. We believe that there is much to be gained by investigating the predictors of national happiness, and how they interact, by going beyond traditional linear models and considering nonlinear models instead.

\section{Implications for Public Policy}

In this section we present the implications and some ideas for how matters can be improved. One key implication for policy makers and decision makers is to focus on improving conditions for people who are experiencing the lowest levels of well-being, this is "to confront the issue of whether an increment to the well-being of a very happy person is worth as much as a similar increment to someone in a miserable state. One solution is to argue that governments should concentrate on creating what could be called a "not bad" society. This means concentrating on getting people out of misery" (O'Donnell, 2013, p.106).

The fact that there are diminishing marginal returns for some factors at the upper end of the achievement scale implies that at the low end the impact of any improvement will be large. This is true at the individual person level as well as at national level. The better fit of the multiplicative model supports the notion that it is the percentage change in a factor that matters, more than an absolute change. For example, a specified dollar increase in salary will be a larger percentage increase for the poor than for an average earner.

A simple and obvious approach for improving matters is to give cash directly to the poor, thus allowing them to decide how to spend it. There is strong evidence that this works. The charity/NGO GiveDirectly has used this approach in rural Kenya, in a randomized control trial. Randomization was at both village and household level (Haushofer and Shapiro, 2016). Large increases in psychological well-being were reported by the study. In particular, questionnaire surveys showed increases in both happiness and life satisfaction, and decreases in both depression and stress. Because the cash transfers were unconditional, there were no costs associated with 'policing' the project.

Another implication from our work arises from the parameter values in the estimated model. Of the six factors considered, improvements in Social Support and in Healthy Life Expectancy will keep adding to happiness for all countries, including those which are highly ranked; this is because the diminution due to decreasing marginal benefit is less pronounced as indicated by the exponents we have estimated being close to unity.

One way of improving social support which is currently gathering interest is known as 'social prescribing'. This involves primary care doctors linking patients with sources of support in the community for the purpose of improving their wellbeing. This may involve people gathering to participate in group activities which promote health and wellbeing. It can also include peer support groups where those who have faced similar adversity can share their guidance and support. For those who live in remote regions, online video communications using services such as Skype can be used for one-to-one or group discussions. This approach could help alleviate anxiety and social isolation. Loneliness reduces wellbeing and is associated with increased depression, a weakened immune system, and higher risk of cardiovascular disease (Hawkley \& Cacioppo, 2010). Thus social support can also have a knock-on effect in supporting physical health. 
One possible cause of the feeling of lack of social support in some countries is the decline of religious communities and their regular gatherings. One alternative that has arisen is The Sunday Assembly, a non-religious community that invites all people, irrespective of belief, to its gatherings, where they sing popular songs, listen to TED-style talks, and make friends over tea and coffee. In between assemblies they also meet at special interest groups e.g. walking, choir, discussion etc. Their motto is 'Live Better, Help Often, and Wonder More'. They have set up such communities in various European countries, North America and Australia. A longitudinal study by Price and Launay (2018) found that those who spent 10 hours per month on Sunday Assembly group activities improved their well-being considerably - sufficient to raise their position by 10 percentiles on the UK Office of National Statistics measure.

One very successful approach for enabling people to get together and share interests or support each other is the Meetup online platform. This has about 35 million users across 180 countries (Toledano, 2017). Anyone can set up a group dealing with a particular interest, other people can join, and real (face-to-face) meetings are then organised. Globally, there are about 140,000 group organizers.

In many countries the support for psychological health takes second place to physical health in health services. There is now a movement towards greater parity between the two amongst general practitioners in the UK National Health Service. 'Parity of esteem' is defined as 'valuing mental health equally with physical health' and appeared in a government report entitled 'No health without mental health' (Britain, 2011). It was later included in the 2012 Health and Social Care (Parliament) Act. Poor mental health can lead to physical health problems, and so treating the former may help avoid the latter. 


\section{APPENDIX}

Table A1. Detailed statistics for the regression in equation (3).

\begin{tabular}{|c|c|c|c|c|}
\hline \multirow[b]{3}{*}{ Parameter } & \multicolumn{3}{|c|}{ Parameter Estimates } & \\
\hline & \multirow[b]{2}{*}{ Estimate } & \multirow[b]{2}{*}{ Std. Error } & \multicolumn{2}{|c|}{ 95\% Confidence Interval } \\
\hline & & & Lower Bound & Upper Bound \\
\hline constant & 2.087 & .735 & .634 & 3.541 \\
\hline b0 & .075 & .101 & -.125 & .275 \\
\hline GDP & .076 & .026 & .024 & .128 \\
\hline SS & .801 & .262 & .283 & 1.319 \\
\hline HLE & .810 & .278 & .260 & 1.360 \\
\hline FREE & .296 & .108 & .083 & .509 \\
\hline GEN & .011 & .019 & -.027 & .049 \\
\hline PER & .020 & .021 & -.022 & .062 \\
\hline
\end{tabular}

R-squared goodness of fit $=82.4 \%$

We observe that the parameters for Generosity and Corruption are not statistically significant - possibly due to the way these factors were estimated - and were removed in the following regression model.

Table A2. Detailed statistics for the regression model equation (4):

\begin{tabular}{|c|c|c|c|c|}
\hline \multicolumn{5}{|c|}{ Parameter Estimates } \\
\hline \multirow[b]{2}{*}{ Parameter } & \multirow[b]{2}{*}{ Estimate } & \multirow[b]{2}{*}{ Std. Error } & \multicolumn{2}{|c|}{ 95\% Confidence Interval } \\
\hline & & & Lower Bound & Upper Bound \\
\hline constant & 2.401 & .026 & 2.350 & 2.452 \\
\hline b0 & .041 & .093 & -.143 & .226 \\
\hline GDP & .087 & .536 & -.973 & 1.146 \\
\hline Ss & .900 & .260 & .386 & 1.414 \\
\hline HLE & .905 & .280 & .351 & 1.459 \\
\hline FREE & .380 & .052 & .276 & .484 \\
\hline
\end{tabular}

We now observe that all four remaining explanatory factors have statistically significant exponents. The R-squared goodness of fit is almost unchanged at $82.2 \%$ 
Table A3. Detailed statistics for the regression in equation (5).

\begin{tabular}{cc|c|c|c}
\multicolumn{5}{c}{ Parameter Estimates } \\
& & & \multicolumn{2}{c}{$95 \%$ Confidence Interval } \\
Parameter & Estimate & Std. Error & Lower Bound & Upper Bound \\
\hline GDP & .093 & .036 & .021 & .165 \\
\hline SS & 1.158 & .411 & .345 & 1.972 \\
\hline HLE & .999 & .319 & .368 & 1.630 \\
\hline FREE & .506 & .157 & .196 & .816 \\
\hline GEN & .037 & .036 & -.034 & .107 \\
\hline PER & .020 & .043 & -.066 & .106 \\
\hline constant & 2.778 & .474 & 1.841 & 3.715 \\
\hline b0 & .013 & .023 & -.032 & .058 \\
\hline
\end{tabular}

R-squared goodness of fit $82.4 \%$

From the above table we note that of the six parameters for the explanatory factors, those associated with corruption and generosity were not statistically significant (as mentioned earlier, this is possibly due to the way these were estimated), and were removed for the following model.

Table A4. Detailed statistics for the regression in equation (6).

\begin{tabular}{|c|c|c|c|c|}
\hline \multirow[b]{3}{*}{ Parameter } & \multicolumn{3}{|c|}{ Parameter Estimates } & \\
\hline & \multirow[b]{2}{*}{ Estimate } & \multirow[b]{2}{*}{ Std. Error } & \multicolumn{2}{|c|}{$95 \%$ Confidence Interval } \\
\hline & & & Lower Bound & Upper Bound \\
\hline GDP & .094 & .033 & .028 & .160 \\
\hline SS & 1.207 & .401 & .413 & 2.001 \\
\hline HLE & 1.035 & .312 & .419 & 1.651 \\
\hline FREE & .537 & .128 & .284 & .791 \\
\hline constant & 2.797 & .426 & 1.956 & 3.639 \\
\hline b0 & .010 & .017 & -.023 & .043 \\
\hline
\end{tabular}

We now see that the four remaining explanatory factors all have significant exponents and the $\mathrm{R}$-squared goodness of fit is almost unchanged at $82.3 \%$. This provides a satisfactory parsimonious model. 


\section{REFERENCES}

1. Britain, G. (2011). No health without mental health: a cross-government mental health outcomes strategy for people of all ages. Stationery Office, UK.

2. Bruni, L. (2007). Handbook on the Economics of Happiness. Edward Elgar Publishing.

3. Carlsen, L. (2017). Happiness as a sustainability factor. The world happiness index: a posetic-based data analysis. Sustainability Science, 1-23.

4. Deaton, A. 2008. Income, Health, and Well Being around the World: Evidence from the Gallup World Poll. Journal of Economic Perspectives 22 (2): 53-72.

5. Dolan, P., Peasgood, T., \& White, M. (2008). Do we really know what makes us happy? A review of the economic literature on the factors associated with subjective well-being. Journal of Economic Psychology, 29(1), 94-122.

6. Dominko, M., \& Verbič, M. (2018). The Economics of Subjective Well-Being: A Bibliometric Analysis. Journal of Happiness Studies, 1-22.

7. Easterlin (1974). Does Economic Growth Improve the Human Lot? Some Empirical Evidence. In Paul A. David and Melvin W. Reder. Nations and Households in Economic Growth: Essays in Honor of Moses Abramovitz. New York: Academic Press, Inc.

8. Easterlin, R. A. (2017). Paradox Lost? Review of Behavioral Economics, 4(4), 311339. doi:10.1561/105.00000068

9. Fortin NI, Helliwell JF, Wang SH. (2015). How does subjective well-being vary around the world by gender and age. World Happiness Report, 42-75.

10. Frey, B. S. (2018). Economics of Happiness. Springer International Publishing.

11. Frey, B. S. and Stutzer, A (eds.). 2013. Recent Developments in the Economics of Happiness. Cheltenham UK: Edward Elgar.

12. Gossen, HH. (1854, English translation 1983). The Laws of Human Relations and the Rules of Human Action Derived Therefrom. MIT Press.

13. Graham, C. (2005). The economics of happiness. World economics, 6(3), 41-55.

14. Haushofer, J., \& Shapiro, J. (2016). The short-term impact of unconditional cash transfers to the poor: experimental evidence from Kenya. The Quarterly Journal of Economics, 131(4), 1973-2042.

15. Hawkley, LC and Cacioppo, JT. (2010). Loneliness matters: A theoretical and empirical review of consequences and mechanisms. Annals of Behavioral Medicine, 40: 218-227. DOI: https://doi.org/10.1007/s12160-010- 9210-8

16. Helliwell, J., Layard, R., \& Sachs, J. (2017). World Happiness Report 2017. New York, NY (USA): UN Sustainable Development Solutions Network. http://worldhappiness.report/wp-content/uploads/sites/2/2017/03/HR17.pdf

17. Helliwell, J., Layard, R., \& Sachs, J. (2013). World Happiness Report 2013. New York, NY (USA): UN Sustainable Development Solutions Network.

18. Helliwell, J., Huang, H., \& Wang, S. (2017). Statistical Appendix for "The social foundations of world happiness", Chapter 2, World Happiness Report 2017. http://worldhappiness.report/wpcontent/uploads/sites/2/2017/03/StatisticalAppendix WHR2017.pdf 
19. Herrero, C, Martinez, R and Villar, A. (2010). Multidimensional social evaluation: an application to the measurement of human development. Review of Income and Wealth, 56(3), 483-497.

20. Jebb, A. T., Tay, L., Diener, E., \& Oishi, S. (2018). Happiness, income satiation and turning points around the world. Nature Human Behaviour, 2(1), 33.

21. Kondraske, GV (2011). General Systems Performance Theory and its application to understanding complex system performance, Information Knowledge Systems Management, 10 (1-4): 235-259.

22. Layard, R., Mayraz, G., \& Nickell, S. (2008). The marginal utility of income. Journal of Public Economics, 92(8-9), 1846-1857.

23. Lootsma, FA (1996). A model for the relative importance of the criteria in the multiplicative AHP and SMART. EJOR, 94, 467-476.

24. Minkov, M. (2009). Predictors of differences in subjective well-being across 97 nations. Cross-Cultural Research, 43(2), 152-179.

25. Minkov, M., \& Bond, M. H. (2017). A genetic component to national differences in happiness. Journal of Happiness Studies, 18(2), 321-340.

26. O’Donnell, G. (2013). Using well-being as a guide to policy. World Happiness Report, 2013, 98-111.

27. OECD. (2013). OECD guidelines on measuring subjective well-being. OECD Publishing, http://dx.doi.org/10.1787/978926419165-en

28. Price, M.E. and Launay, J. (2018). Increased Wellbeing from Social Interaction in a Secular Congregation. Secularism and Nonreligion, 7(1), article 6, p.1-9. DOI: http://doi.org/10.5334/snr.102

29. Rojas, M. (2018). Happiness in Latin America has social foundations. Chapter 6 of World Happiness Report 2018.

30. Sachs, J. D., Layard, R., \& Helliwell, J. F. (2018). World Happiness Report 2018 (No. id: 12761). UN Sustainable Development Solutions Network.

31. Toledano, M (2017). Emergent Methods: Using netnography in public relations research. Public Relations Review. 43 (3): 597-604.

32. Tofallis, C. (2013). An automatic-democratic approach to weight setting for the new human development index. Journal of Population Economics, 26(4), 1325-1345.

33. Tofallis, C. (2014). Add or multiply? A tutorial on ranking and choosing with multiple criteria. INFORMS Transactions on Education, 14(3), 109-119.

34. United Nations, (2011). Happiness: towards a holistic approach to development. Resolution 65/309 adopted by the General Assembly on 19 July 2011. https://web.archive.org/web/20180326023420/http://repository.un.org/bitstream/handl e/11176/291712/A_RES_65_309-EN.pdf?sequence=3\&isAllowed=y

35. Weimann, J., A. Knabe, and R. Schob. (2016). Measuring Happiness: The Economics of Well-Being. Cambridge, MA: MIT Press.

36. Ye, D., Ng, Y. K., \& Lian, Y. (2015). Culture and happiness. Social Indicators Research, 123(2), 519-547. 